\title{
DEHYDRATION AND REHYDRATION OF AN ION-LEACHABLE GLASS USED IN GLASS-IONOMER CEMENTS
}

\author{
JACEK KLOS*, BEATA CZARNECKA**, ${ }^{\#}$ JOHN W. NICHOLSON*** \\ *Department of Physical Chemistry, Faculty of Chemistry, Adam Mickiewicz University of Poznań, \\ ul. Umultowska 89b, 61-614 Poznan, Poland \\ **Department of Biomaterials and Experimental Dentistry, Dental Institute, University of Medical Sciences, \\ ul Bukowska 70, 60-812 Poznan, Poland \\ ***Bluefield Centre for Biomaterials, 67-68 Hatton Garden, London, EC1N 8JY, United Kingdom and Dental Physical Sciences, \\ Barts \& The London School of Medicine and Dentistry, Queen Mary University of London, \\ Mile End Road, London, E1 4NS, United Kingdom \\ "E-mail: john.nicholson@bluefieldcentre.co.uk
}

Submitted October 13, 2016; accepted February 2, 2017

\begin{abstract}
Keywords: Glass-ionomers; Glass; Dehydration; Rehydration; Compressive strength
Samples of the ionomer glass known as G338 have been heated at $240{ }^{\circ} \mathrm{C}$ for 24 hours, after which they lost $1.19 \%$ (Standard deviation $0.16 \%$ ) of their original mass. This loss was attributed to removal of water, as both molecular water and the product of reaction of silanol groups to form siloxane bridges. Exposing samples of glass either to air at ambient humidity or to air at 95\% relative humidity showed a degree of rehydration, but mass uptake did not approach the original mass loss in either case. It is suggested that this is because of the relatively difficulty in forming new silanol groups from the siloxane bridges. Glass-ionomer cements prepared from these glass samples with aqueous poly(acrylic acid) solution had different properties, depending on the glass used. Dehydrated glass gave cements which set faster but were weaker than those formed by as-received glass. The role of silanol groups in influencing reaction rate and promoting strength development is discussed.
\end{abstract}

\section{INTRODUCTION}

Of the materials available for use by dentists to repair teeth damaged by decay (caries) one is the glass-ionomer cement $[1,2]$. This material can be used for various parts of the restoration process of teeth, including as liners and bases, and also as full restorations [2, 3]. Glassionomer cement also finds application preventively as pit-and-fissure sealants in newly erupted molars, and in orthodontics as an adhesive for brackets [2].

Glass-ionomer cement is a hybrid material that comprises an organic polymer, such as poly(acrylic acid), and a ceramic phase, namely the glass [4]. The glass employed is a special ion-leachable material that undergoes an acid-base reaction when treated with an aqueous solution of the poly(acrylic acid) component $[3,4]$. This leads to the release of metal ions from the glass, followed by formation of metal carboxylate groups on the polymer chain [6-8]. These metal carboxylates cross-link the polymer molecules and the resulting structure becomes rigid and inflexible, thus causing the whole mass to set to form a hard and reasonably strong solid [9].

Following the initial hardening, the cement undergoes a set of processes known as maturation. Various changes occur on maturation, including an improvement in the translucency [10] and an increase in the proportion of water within the cement that is tightly bound [4, 11]. The latter phenomenon has recently been attributed to the hydration of $-\mathrm{Si}-\mathrm{O}-\mathrm{Si}-$ units in the surface layers of the glass powder to form adjacent silanol (-Si-OH) groups [12]. This suggestion is consistent with the observation from FTIR spectroscopy that silanol groups are detectable in set glass-ionomer cements [13]. Similar hydration processes are known to occur in both silica [14] and silicate glass [15], and there is a strong likelihood of them occurring in the alumino-silicate glasses used to fabricate glass-ionomer cements.

In a recent study, the susceptibility to hydration of one particular ionomer glass, so-called G338, was studied. Experiments involved preparing slurries of glass powder with water and allowing them to set [12]. Resulting mixtures had a degree of structural integrity, but were found to be extremely weak in compression, with strengths of less than $1 \mathrm{MPa}$ in specimens aged for 4 weeks. These mixtures appear to retain their shape under gravity due to hydrogen bonding between layers of water in the spaces between the glass particles. Raman spectroscopy could detect no changes following interaction with water, partly because even the nominally "dry" glass powder had bands in the region 2860-2867 $\mathrm{cm}^{-1}$, which are known to arise from strong hydrogen bonds between silanol groups and water molecules [16]. This suggests that even apparently dry G338 powder has a film of water on the surface of its particles [12]. 
The present study has been carried out in order to investigate this possibility further. Samples of the glass G338 were dried at $240^{\circ} \mathrm{C}$ for $24 \mathrm{~h}$, after which they were allowed to rehydrate in air at room temperature and either ambient humidity or 95\% RH. Dehydrated G338 was used to prepare cement specimens and the setting time and compressive strength at $24 \mathrm{~h}$ were compared with those of a cement made from "as-received" G338. Finally, the effect of drying at lower temperatures on the compressive strength of resulting cements was determined for a series of temperatures. The results obtained give further information about the importance of the hydration state of the glass in influencing the properties of the glass-ionomer cement made from it.

\section{MATERIALS AND METHODS}

All of the experiments in this study used the ionomer glass G338, obtained from First Scientific Dental, Elmshorn, Germany). Table 1 lists the pre-firing composition of this glass, which is of the type widely used in commercial glass-ionomer cements.

Samples of G338 of mass $0.45-0.75 \mathrm{~g}$ were desiccated by heating on aluminium boats at $240^{\circ} \mathrm{C}$ for $24 \mathrm{~h}$, their mass before and after heating being recorded. Samples of this glass powder were treated in two ways, either stored in air at ambient humidity, or stored in a humidity chamber over saturated potassium nitrate solution, which gives a relative humidity of $95 \%$ [17] Sets of six glass powders were used in each case, and they were weighed at regular intervals up to 168 hours.

Samples of as-received and G338 glass were used to prepare experimental glass-ionomer cements by mixing with poly(acrylic acid) solution in a ratio of 3:1 glass powder to polymer solution. The poly(acrylic acid) solution used was Ionofil liquid (VOCO, Lichtenstein; Lot number 1451244), which contains approximately $45 \%$ polymer by mass.

For these cements, setting time was determined using the Gillmore needle method specified in the ISO standard ISO9917 [18]. This method uses a weighted needle (mass $50 \mathrm{~g}$ ), and the cement is considered set once this needle fails to leave a mark on the cement.

Table 1. Pre-firing composition of glass G338.

\begin{tabular}{cr}
\hline Component & $\%$ \\
\hline $\mathrm{SiO}_{2}$ & 24.9 \\
$\mathrm{Al}_{2} \mathrm{O}_{3}$ & 14.2 \\
$\mathrm{Na}_{3} \mathrm{AlF}_{6}$ & 19.2 \\
$\mathrm{CaF}_{2}$ & 12.8 \\
$\mathrm{AlF}_{3}$ & 4.6 \\
$\mathrm{AlPO}_{4}$ & 24.2 \\
Other oxides & 0.1 \\
\hline
\end{tabular}

The material was ground to a fine powder, mean particle size approximately 4 um (87.7\% at $10 \mu \mathrm{m}$ or less)
Compressive strengths were also determined for these cements, specimens being prepared as cylindrical samples of dimensions $6 \mathrm{~mm}$ height $\mathrm{x} 4 \mathrm{~mm}$ diameter in sets of six. Compressive strength was determined after storing the cylinders in water at room temperature for 24 hours.

Results were expressed as means and standard deviations. Differences between values were tested for significance using the Student t-test.

\section{RESULTS}

The mean loss in mass on heating samples of G338 for 24 hours at $240^{\circ} \mathrm{C}$ was $1.19 \%$ (Standard deviation $0.16 \%$ ). Figures for mass regain after $168 \mathrm{~h}$ (1 week) in their respective conditions are shown in Table 2 . These are calculated in terms of the original mass of the glass, so are directly comparable with the mass loss result previously stated.

Table 2. Mass regain of desiccated samples of glass G338

\begin{tabular}{lcc}
\hline Sample & $\begin{array}{c}\text { Mean regain } \\
(\%)\end{array}$ & $\begin{array}{c}\text { Standard deviation } \\
(\%)\end{array}$ \\
\hline Ambient humidity & 0.18 & 0.11 \\
$95 \%$ RH & 0.43 & 0.21 \\
\hline
\end{tabular}

Both mass regain figures are significantly lower than the mass originally lost $(p<0.001)$, though they do not differ significantly from each other. This shows that the desiccated samples are able to take up some of the mass lost on heating, but not all of it in either case, despite the long time period used.

Samples of glass were used to form cements, and results for these cements are shown in Table 3. These results show that the cement formed from the as-received glass had a significantly longer setting time $(p<0.001)$ and set to give samples with significantly greater strength $(\mathrm{p}<0.001)$.

Table 3. Properties of cements made from desiccated samples of glass G338

\begin{tabular}{lcc}
\hline \multirow{2}{*}{ Sample } & \multicolumn{2}{c}{ Standard deviation } \\
\cline { 2 - 3 } & $\begin{array}{c}\text { Setting time } \\
(\mathrm{min})\end{array}$ & $\begin{array}{c}\text { Compressive strength } \\
(\mathrm{MPa})\end{array}$ \\
\hline Ambient humidity & 0.18 & 0.11 \\
$95 \% \mathrm{RH}$ & 0.43 & 0.21 \\
\hline
\end{tabular}




\section{DISCUSSION}

The mass loss recorded for the glass G338 on heating at $240^{\circ} \mathrm{C}$ for 24 hours can be attributed to loss of water. There are two possible origins for this water, namely molecular water bound to the surface of the glass particles, and water generated by dehydration of adjacent silanol groups on the surface to form siloxane bridges, i.e.

$$
-\mathrm{Si}-\mathrm{OH}+\mathrm{HO}-\mathrm{Si}-\rightarrow-\mathrm{Si}-\mathrm{O}-\mathrm{Si}-+\mathrm{H}_{2} \mathrm{O}
$$

Both sources of water are consistent with previous observations using Raman spectroscopy [12] that both molecular water and silanol groups are present in samples of G338 powder. They are presumably located on the surfaces of the individual glass particles.

Mass regain data also support the suggestion that there are two possible forms of water. Regains in $168 \mathrm{~h}$ ( 1 week) varied from $0.18 \%$, the mean in air at ambient humidity, to $0.43 \%$, the mean in air at $95 \%$ relative humidity. In neither case did the mass regain approach the earlier mass loss. A possible explanation for this is that replacing the molecular water on the particle surfaces is straightforward, but reversing the dehydration of silanol groups via hydration of siloxane bridges is more difficult. Recent studies have suggested that, on silica at least, both processes are able to occur [19], but our results suggest that the latter does not occur readily on this particular ionomer glass.

Cements made from the glasses show interesting differences. The dehydrated glass gave cements that set more rapidly than those made from the as-received glass, yet were weaker when set. This is an unusual observation, since it is generally the case that steps that reduce the speed of set also lead to weaker cements [2, 20]. It is worth considering this finding in some detail.

It is known that the glass G338 is partially phaseseparated [21], having undergone a process known as spinodal decomposition on cooling [22]. This results in the formation of two phases, which are not completely separated, one of which is more susceptible to acid attack [23]. These susceptible sites are relatively rich in calcium ions, and the removal of these ions from the glass followed by formation of carboxylate cross-links is the first step in the setting of glass-ionomer cements [24]. The formation of siloxane bridges may increase the accessibility of calcium ions, and this might be why the rate of reaction is greater with dehydrated glass powder.

However, despite this increased rate of setting, the final cements were weaker than those made with as-received glass. This suggests that the silanol groups on the glass surface make a contribution to the eventual strength of the set cement. The reaction with the polyacid solution is likely to promote some formation of silanol groups on the dehydrated glass as the setting reaction proceeds, but this does not result in high strength cements. It is known that silanol groups are able to become involved in a range of hydrogen-bonded environments [25] and also that hydrogen bonds formed by silanol groups with water are stronger than hydrogen bonds in bulk water [26]. However, the fact that they need to be formed in situ within the cement made from dehydrated glass seems to inhibit their usefulness in promoting high strength in the set cement. The net effect is that, though they probably form in cements made from both as-received and dehydrated glass, in the latter there are probably too few to be effective in enhancing strength.

\section{CONCLUSIONS}

Treating the ionomer glass $\mathrm{G} 338$ at $240^{\circ} \mathrm{C}$ for 24 hours was found to lead to a mass loss of $1.19 \%$, a result attributed to loss of water. Mass regain studies were consistent with the idea that water as molecular water could be replaced readily, but water arising from dehydration of silanol groups to form siloxane groups was much less easy to replace.

Cements made from dehydrated glass set more quickly but were weaker than cements made from asreceived glass. These results are attributed to the effects of silanol groups, the absence of which in dehydrated glass increases the accessibility of calcium ions to acid attack. However, since silanol groups can form strong hydrogen bonds, notably with water, their absence (or reduced amount) in dehydrated glass led to a weakening of the set cement made from this glass.

These findings confirm that the hydration state of the glass component is important in controlling the properties of the resulting glass-ionomer cements.

\section{REFERENCES}

1. Mount G.J. (2002). Color atlas of glass ionomer cement. $2^{\text {nd }}$ ed. Martin Dunitz.

2. Nicholson J.W., Czarnecka B. (2016). Materials for the direct restoration of teeth. Woodhead Publishing.

3. Lindemeyer R.G. (2007): The use of glass ionomer sealants on newly erupting permanent molars. Journal of the Canadian Dental Association 73, 131-134.

4. Wilson A.D., McLean J.W. (1988). Glass ionomer cement. Quintessence Pub Co.

5. Prentice L. H., Tyas M. J., Burrow M. F. (2007): Ion leaching of a glass-ionomer glass: an empirical model and effects on setting characteristics and strength. Journal of Materials Science: Materials in Medicine, 18(1), 127-131. doi: 10.1007/s10856-006-0670-0

6. Crisp S., Pringuer M. A., Wardleworth D., Wilson A. D. (1974): Reactions in glass ionomer cements: II. An infrared spectroscopic study. Journal of dental research, 53(6), 1414-1419.

7. Nicholson J. W., Brookman P. J., Lacy O. M., Wilson, A. D. (1988): Fourier transform infrared spectroscopic study of the role of tartaric acid in glass-ionomer dental cements. Journal of dental research, 67(12), 1451-1454. 
8. Nicholson J.W., Sidhu S.K. (2016): A review of glassionomer cements for clinical dentistry, Journal of Functional Biomaterials, 7(3), 16; doi 10.3390/jfb7030016

9. Crisp S., Wilson A. D. (1974): Reactions in glass ionomer cements: III. The precipitation reaction. Journal of dental research, 53(6), 1420-1424.

10. Zainuddin N., Karpukhina N., Hill R. G., Law, R. V. (2009): A long-term study on the setting reaction of glass ionomer cements by $27 \mathrm{Al}$ MAS-NMR spectroscopy. dental materials, 25(3), 290-295. doi: 10.1016/j.dental. 2008.07.008

11. Wilson A.D., Nicholson J.W. (1993). Acid-base cements. Cambridge University Press.

12. Klos J., Czarnecka B., Nicholson J.W. (2016): The hydration of an ion-leachable glass used in glass-ionomer cements. Ceramics-Silikaty, 60, 243-247. doi: $10.13168 /$ cs. 2016.0036

13. Matsuya S., Maeda T., Ohta M. (1996): IR and NMR analyses of hardening and maturation of glass-ionomer cement. Journal of dental research, 75(12), 1920-1927.

14. Zhuravlev L. T. (2000): The surface chemistry of amorphous silica. Zhuravlev model. Colloids and Surfaces A: Physicochemical and Engineering Aspects, 173(1), 1-38. doi: 10.1016/S0927-7757(00)00556-2

15. Tadjiev D. R., Hand R. J. (2010): Surface hydration and nanoindentation of silicate glasses. Journal of Non-Crystalline Solids, 356(2), 102-108. doi: 10.1016/j.jnoncrysol. 2009.10.005

16. Zarubin D. P. (1999): Infrared spectra of hydrogen bonded hydroxyl groups in silicate glasses. A re-interpretation. Physics and Chemistry of Glasses, 40(4), 184-192.

17. Lange N.R. (1961). Handbook of Chemistry. McGraw-Hill.

18. International Organization for Standardization. ISO9917 Dental water based cements, 2008.
19. Warring S. L., Beattie D. A., McQuillan A. J. (2016): Surficial siloxane-to-silanol interconversion during roomtemperature hydration/dehydration of amorphous silica films observed by ATR-IR and TIR-raman spectroscopy. Langmuir, 32(6), 1568-1576. doi: 10.1021/acs.langmuir. 5b04506

20. Nicholson J. W. (1998): Chemistry of glass-ionomer cements: a review. Biomaterials, 19(6), 485-494. doi: 10.1016/S0142-9612(97)00128-2

21. Pedersen M. T., Tian K. V., Dobó-Nagy C., Chass G. A., Greaves G. N., Yue Y. (2015): Phase separation in an ionomer glass: insight from calorimetry and phase transitions. Journal of Non-Crystalline Solids, 415, 24-29. doi: 10.1016/j.jnoncrysol.2015.02.012

22. Wood D. J., Hill R. G. (1991): Structure-property relationships in ionomer glasses. Clinical materials, 7(4), 301-312. doi: 10.1016/0267-6605(91)90074-P

23. Barry T. I., Clinton D. J., Wilson A. D. (1979): The Structure of a Glass-Io nomer Cement and its Relationship to the Setting Process. Journal of Dental Research, 58(3), 1072-1079.

24. Pires R., Nunes T. G., Abrahams I., Hawkes G. E., Morais C. M., Fernandez, C. (2004): Stray-field imaging and multinuclear magnetic resonance spectroscopy studies on the setting of a commercial glass-ionomer cement. Journal of Materials Science: Materials in Medicine, 15(3), 201208. doi: 10.1023/B:JMSM.0000015479.65516.d0

25. McMillan P. F., Remmel, R. L. (1986): Hydroxyl sites in $\mathrm{SiO}_{2}$ glass: A note on infrared and Raman spectra. American Mineralogist, 71(5-6), 772-778.

26. Pantalei C., Senesi R., Andreani C., Sozzani P., Comotti A., Bracio S., Beretta M., Sokol P.E., Reiter G. (2011). Interaction of single water molecules with silanols in mesoporous silica. Physical Chemistry Chemical Physics, 13(13), 6022-6028. doi: 10.1039/C0CP02479A 